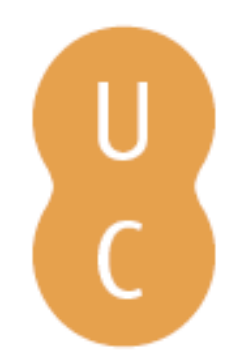

\title{
nommalina
}

\section{Inéditos viáveis para os trabalhadores jovens e adultos nas políticas atuais de Educação Profissional e Tecnológica do Brasil}

Autor(es): $\quad$ Santos, Simone Valdete dos

Publicado por: Imprensa da Universidade de Coimbra

URL

persistente: URI:http://hdl.handle.net/10316.2/41303

DOI: $\quad$ DOI:https://doi.org/10.14195/978 98926 1326-0_14

Accessed : $\quad$ 26-Apr-2023 14:30:40

A navegação consulta e descarregamento dos títulos inseridos nas Bibliotecas Digitais UC Digitalis, UC Pombalina e UC Impactum, pressupõem a aceitação plena e sem reservas dos Termos e Condições de Uso destas Bibliotecas Digitais, disponíveis em https://digitalis.uc.pt/pt-pt/termos.

Conforme exposto nos referidos Termos e Condições de Uso, o descarregamento de títulos de acesso restrito requer uma licença válida de autorização devendo o utilizador aceder ao(s) documento(s) a partir de um endereço de IP da instituição detentora da supramencionada licença.

Ao utilizador é apenas permitido o descarregamento para uso pessoal, pelo que o emprego do(s) título(s) descarregado(s) para outro fim, designadamente comercial, carece de autorização do respetivo autor ou editor da obra.

Na medida em que todas as obras da UC Digitalis se encontram protegidas pelo Código do Direito de Autor e Direitos Conexos e demais legislação aplicável, toda a cópia, parcial ou total, deste documento, nos casos em que é legalmente admitida, deverá conter ou fazer-se acompanhar por este aviso. 


\section{INÉDITOS VIÁVEIS PARA OS TRABALHADORES JOVENS E ADULTOS NAS POLÍTICAS ATUAIS DE EDUCAÇÃO PROFISSIONAL E TECNOLÓGICA DO BRASIL}

Simone Valdete dos Santos 52

\section{Resumo}

A colocação do Brasil como sétima economia mundial promove a importância da Educação Profissional e Tecnológica, considerando os 110 milhões de brasileiros sem Educação Básica, conforme registros do censo demográfico de 2010.

A complexidade das políticas de Educação Profissional e Tecnológica afere cenários para efetivação do Programa Nacional de Educação Profissional integrada à Educação Básica na Modalidade Educação de Jovens e Adultos (PROEJA).

A análise considera o contexto atual das políticas de Educação Profissional e Tecnológica para a inclusão dos trabalhadores, a efetivação do PROEJA, as iniciativas do PRONATEC (Programa Nacional de Acesso ao Ensino Técnico e ao Emprego) recentemente instituído, as possibilidades de articulação destas políticas, os limites e as possibilidades de constituírem-se como inéditos

52 Faculdade de Educação - UFRGS; simonevaldete@gmail.com 
viáveis, conforme o entendimento freireano, para inclusão de jovens e adultos trabalhadores.

\begin{abstract}
The placement of Brazil as the $7^{\text {th }}$ biggest world economy promotes the importance of Vocational and Technological Education, taking in consideration the 110 million Brazilians without Basic Education, according to registers of population census of 2010. The complexity of Vocational and Technological Education policies assesses scenarios for the realization of the National Program of Vocational Education, integrated into the Basic Education in the modality of Youth and Adult Education (PROEJA).

This paper analysis considers the current context of Vocational and Technological Education policies for the inclusion of workers; the development of PROEJA; initiatives of PRONATEC (National Program for Access to Technical Education and Employment), recently instituted; possibilities of articulation between these policies; limits and possibilities of placing themselves as unknown-viable ways, as Freire's understanding, for the inclusion of young and adult workers.
\end{abstract}


Os dados do último censo demográfico, ano de 2010, revelam que a metade dos brasileiros $(50,2 \%)$ com idade acima de 10 anos, ou seja, 81,3 milhões de pessoas não conseguiram completar o ensino fundamental, referente a nove anos na escola. Com Ensino Médio incompleto são mais 28,7 milhões. Ao todo, portanto, são 110 milhões de brasileiros sem Educação Básica.

Por outro lado, pesquisa recente da Fundação Getúlio Vargas baseada em dados da Pesquisa Mensal de Emprego / IBGE no acumulado dos anos 2002 a 2010 afirma que cursos profissionalizantes de Formação Inicial e Continuada (FIC) não atingem empregabilidade tampouco níveis salariais melhores para os trabalhadores, já a elevação de escolaridade, sobretudo nível médio corrobora para o aumento salarial em até $50 \%$ tratando-se de vagas de emprego no serviço público.

O Programa Nacional de Educação Profissional integrada à Educação Básica na Modalidade Educação de Jovens e Adultos (PROEJA) completa nove anos de existência. Regulamentado pelo decreto presidencial 5840 de 2006 do Governo Lula, atua neste cenário de baixa escolaridade e necessidade de Educação Profissional e Tecnológica, com oferta de nível fundamental - o denominado PROEJA FIC (Formação Inicial e Continuada) e nível médio.

O PROEJA inaugurou as políticas de inclusão dos trabalhadores no âmbito da Secretaria de Educação Profissional e Tecnológica do Ministério da Educação (SETEC/MEC) traduzidas também no Programa Mulheres Mil voltado para mulheres em situação de extrema pobreza em cursos de formação profissional, alternativas de economia solidária, bem como pela implantação do CERTIFIC, regulamentado pela portaria interministerial 1.082 (Ministério da Educação e Ministério do Trabalho e Emprego) de 20 de novembro de 2009, o qual consiste no reconhecimento e certificação dos saberes profissionais dos trabalhadores com o mínimo de Ensino Fundamental completo em cinco áreas profissionais: Pesca, Turismo e Hospitalidade, Eletroeletrônica, 
Construção Civil e Música, vinculado atualmente aos Institutos Federais de Educação Profissional, Ciência e Tecnologia, tendo potencial para acreditação das demais redes de Educação Profissional e Tecnológica, especialmente as redes estaduais.

O PROEJA possui 66.661 matrículas conforme dados do SISTEC de $2011^{53}$, ocorre predomínio da oferta gratuita nas redes públicas federal, estaduais e municipais de ensino, somente 4.946 desta oferta é privada.

Compõem objetivo número 0588 do Plano Plurianual (2012-2015) aprovado no Congresso Nacional: "Ofertar vagas de educação profissional para jovens e adultos articulada com a elevação de escolaridade e realizar processos de reconhecimento de saberes e certificação profissional." Sendo as metas de 2012 a 2015 - ampliar a oferta de cursos de profissionalização articulados com elevação de escolaridade, especialmente para mulheres em situação de vulnerabilidade social, atendendo a 100 mil mulheres; - ampliar a oferta de programas de reconhecimento de saberes para fins de certificação profissional em formação inicial e continuada e técnico de nível médio; - elevar o percentual de matrículas de educação de jovens e adultos na forma integrada à educação profissional, no intuito de alcançar a meta 10 do Plano Nacional de Educação 2011-2020.

Estando vinculado às iniciativas 02B3: "Ampliação da oferta de cursos de formação inicial e continuada e técnico de nível médio articulada com educação de jovens e adultos (EJA), de ensino fundamental e médio, e do acesso do trabalhador a processo de reconhecimento de saberes, nas redes de educação profissional e tecnológica, possibilitando, inclusive, recorte de gênero e atendimento de públicos específicos, inclusive com ações de fomento e apoio com vistas à

53 As matrículas das redes de Educação Profissional e Tecnológica estão informadas e monitoradas no SISTEC (Sistema Nacional de Informações da Educação Profissional e Tecnológica), administrado pela Secretaria de Educação Profissional e Tecnológica do Ministério da Educação, foram disponibilizados os dados do ano 2011. 
reestruturação didático-pedagógica, produção de material didático, capacitação de docentes e permanência do estudante".

Desta forma, o PROEJA estava assegurado no plano plurianual com escopo diferenciado de financiamento: material didático, capacitação de docentes, assistência estudantil para permanência do estudante. Vinculado ao CERTIFIC pela elevação de escolaridade de no mínimo ensino fundamental, o equivalente a nove anos de estudo, também vinculado a certificação profissional, podendo estar focado em públicos específicos, como por exemplo: catadores de resíduos sólidos, indígenas, pescadores, agricultores familiares, entre outros.

A meta 10 do Plano Nacional de Educação, aprovado pela lei 13.005/2014 contempla o PROEJA: oferecer no mínimo vinte e cinco por cento das matrículas de Educação de Jovens e Adultos na forma integrada à Educação Profissional nos anos finais do ensino fundamental e no ensino médio. Tal acúmulo de $25 \%$ das matrículas representa até 2020 o quantitativo previsto de 950 mil matrículas de PROEJA, considerando o acúmulo de 35 mil matrículas quando da elaboração da proposta do PNE em 2011.

O PROEJA é anterior ao PRONATEC (Programa Nacional de Acesso ao Ensino Técnico e ao Emprego) instituído pela Lei 12.513, de 26 de outubro de 2011 do governo Dilma Rousseff.

Das 7,4 milhões de matrículas criadas pelo PRONATEC (Programa Nacional de Acesso ao Ensino Técnico e Emprego), há registros oficiais de cerca de 950 mil desistências, evasão de outubro de 2011 até junho de 2014, a presidenta anunciou 15 milhões de novas vagas para 2015.

O quantitativo de matrículas do PRONATEC é audacioso se considerarmos a oferta de 1 milhão e 514 mil e 794 de matrículas públicas e privadas do ano de 2011 em cursos técnicos, conforme dados do censo escolar, a oferta alcançada pelo PROEJA até então, mas quantitativo insuficiente se considerarmos a demanda de escolarização básica da população com 10 anos e mais. 
O PROEJA ocorre nas redes públicas de ensino, estava previsto no orçamento da União até 2015 através do plano plurianual, compõem a meta 10 do Plano Nacional de Educação.

O presente texto discorrerá sobre as atuais políticas de Educação Profissional e Tecnológica de inclusão dos trabalhadores e a efetivação do PROEJA: possibilidades de articulação destas políticas, resultados efetivos possíveis, considerando as ações propostas pelo PRONATEC.

\section{A Bolsa Formação}

A lei do PRONATEC - 12.513/2011 em seu artigo $4^{\circ}$ regulamentava a bolsa formação em seu inciso IV nas modalidades: a) Bolsa-Formação Estudante; e b) Bolsa-Formação Trabalhador.

A bolsa formação estudante ocorria na concomitância do Ensino Médio, podendo ser realizada na oferta de Educação de Jovens e Adultos (EJA). Situação que exigia da instituição uma proposta pedagógica para o estudante trabalhador, sobretudo do noturno, o qual precisava comparecer três turnos na formação geral, outros dois turnos no curso de Educação Profissional, por exemplo, não podendo disponibilizar todos os turnos como um estudante não trabalhador do Ensino Médio Regular, no turno inverso a sua frequência ao Ensino Médio.

A meta prevista ${ }^{54}$ do PRONATEC consistia na oferta de 411 mil e 190 vagas da bolsa formação estudante, ou seja, cursos de nível médio técnico e 2 milhões, 574 mil e 102 de vagas nos cursos de Formação Inicial e Continuada (FIC) até 2014.

${ }^{54}$ Dados fornecidos pelo então Secretário de Educação Profissional e Tecnológica Marco Antônio de Oliveira, em palestra sobre o PRONATEC, no II Fórum Mundial de Educação Profissional e Tecnológica em Florianópolis/SC nos dias 28, 29,30,31/05 e $01 / 6 / 2012$. 
As instituições ofertantes da bolsa formação correspondiam às unidades do Sistema S, sobretudo SENAI, SENAC e SENAR ${ }^{55}$, a rede federal de Educação Profissional e Tecnológica, contando com a adesão em 2012 das redes estaduais ${ }^{56}$.

O financiamento da bolsa formação correspondia à $R \$ 10,00$ por hora- aula e por aluno na turma, correspondendo ao investimento em material didático, assistência estudantil (auxílio transporte e merenda do estudante), pagamento de professor e coordenador das turmas ${ }^{57}$. A instituição ofertante precisava estar com laboratórios, salas de aula disponíveis para oferta, não sendo tal infraestrutura subsidiada, correspondendo à contrapartida da instituição ofertante dos cursos vinculados à bolsa formação ${ }^{58}$.

A adesão das redes estaduais foi negociada no segundo semestre de 2012 para que ministrassem os cursos da concomitância dos estudantes do Ensino Médio e da Formação Inicial e Continuada, recebendo assim os recursos advindos da bolsa formação estudante e da bolsa formação trabalhador os quais estavam sendo alocados para o Sistema S e rede federal de Educação Profissional e Tecnológica.

\footnotetext{
55 Respectivamente: Serviço Nacional de Aprendizagem Industrial, Serviço Nacional do Comércio, Serviço Nacional de Aprendizagem Rural. Tais instituições compõem o denominado "Sistema S" os quais ministram Educação Profissional e Tecnológica, sendo o SENAR vinculado à formação inicial e continuada, não possui experiência na oferta de cursos técnicos de nível médio.

56 Não foram todas as redes estaduais as quais se habilitaram para ofertar cursos na modalidade bolsa formação do PRONATEC. O Estado do Rio Grande do Sul, com todo o potencial de sua rede de escolas, não aderiu, não ofertou cursos FIC e tampouco de nível médio com subsídios da bolsa formação.

57 Um curso de formação inicial e continuada de 160 horas aula, que é o mínimo conforme o Guia PRONATEC de cursos, com 30 alunos em sala de aula compõe o financiamento de $R \$ 48$. 000,00, sendo daí retirado o pagamento das horas do docente, material didático, assistência estudantil. Diante da atual crise política e financeira a qual passa o Brasil serão cortados recursos do PRONATEC em 2015, sobretudo na ação "bolsa formação".

58 Informações constantes no site: http://pronatec.mec.gov.br/ acesso em 10 de outubro de 2012.
} 
Durante a reunião promovida pela SETEC/MEC no dia 24 de maio de 2012 no Instituto Federal de Educação Profissional e Tecnológica de Brasília (IFB), a proposta foi à vinculação da oferta de PROEJA na rede estadual com a bolsa formação estudante e trabalhador, ou seja, a articulação com elevação de escolaridade, na compreensão que apenas o curso FIC não dispõem de condições de empregabilidade para o trabalhador, considerando a existência de uma Superintendência 59 específica gestora da Educação Profissional e Tecnológica no Estado. Tal processo de adesão estava em negociação do Conselho Nacional dos Secretários Estaduais de Educação (CONSED) junto à Secretaria de Educação Profissional e Tecnológica (MEC).

Da mesma forma, a construção do Catálogo Nacional de Cursos de Formações Iniciais e Continuadas - Catálogo Nacional de Cursos FIC, na substituição do Guia de Cursos PRONATEC, o qual, regulamentava o financiamento dos cursos FIC do PRONATEC, dependendo de sua formulação, poderá oportunizar a construção de itinerários formativos pelos trabalhadores, conforme as terminalidades técnicas, definidas pelas atuais Diretrizes Curriculares da Educação Profissional Técnica de Nível Médio, constantes no parecer 11 de 2012 da Câmara de Educação Básica. Sendo possível por esta regulamentação o ingresso dos trabalhadores em cursos técnicos, ocorrendo a valorização da carga horária de cursos FIC, eventualmente frequentados. Desta feita, os cursos FIC podem incorporar cargas horárias nos respectivos cursos técnicos, dos eixos tecnológicos correspondentes.

59 O Rio Grande do Sul, na contramão das políticas de expansão de Educação Profissional e Tecnológica, diante de uma rede de 141 escolas estaduais de Educação Profissional extinguiu em 2012 a Superintendência da Educação Profissional (SUEPRO) sob alegação de uma política articuladora do Ensino Médio, o que resulta em um tratamento generalista das escolas de Educação Profissional no conjunto de cerca de 1.100 escolas de Ensino Médio. Em 2015 foi recuperada a Superintendência e a especificidade das políticas vinculadas as escolas de Educação Profissional e Tecnológica. 
A bolsa formação estava organizada mediante a instituição ofertante - rede federal, sistema $S$, redes estaduais e instituição demandante - ou seja - a instituição que encaminhava alunos e fazia a pré-matrícula no Sistema Nacional de Informações da Educação Profissional e Tecnológica (SISTEC) dos alunos da bolsa formação.

Conforme o Manual de Operações do SISTEC - bolsa formação estudante e bolsa formação trabalhador: - O Sistema de Informações da Educação Profissional e Tecnológica - SISTEC é um sistema informatizado do Governo Federal cujo objetivo é promover mecanismos de registro e controle dos dados da educação profissional e tecnológica no país. O SISTEC foi desenvolvido em 2008 com início de operação em 2009, por força da Resolução do CNE/CEB $N^{\circ}$ 4/99. Desde então, os dados referentes à educação profissional e tecnológica ficam concentrados no SISTEC. Assim, a gestão da ação Bolsa-Formação do Programa PRONATEC estão incorporadas no SISTEC, na aba Pronatec. (http://sitesistec.mec.gov.br/ manual de Operação do Sistec (Bolsa-Formação Estudante e Bolsa-Formação Trabalhador - acesso em 03 de outubro de 2012).

No processo de negociação do PRONATEC o Ministério de Desenvolvimento Social e Combate à Fome (MDS) compõem uma instituição demandante, sendo que os Centros de Referência de Assistência Social (CRAS) de prefeituras selecionadas por este ministério, as quais possuíam um número significativo de famílias que recebiam transferência de renda (bolsa família, Benefício de Prestação Continuada - BPC), constando uma senha para colocação de uma pré-matrícula no SISTEC, da mesma forma as Secretarias Estaduais de Educação com os estudantes da concomitância do Ensino Médio, o Ministério do Turismo com cursos na sua área, o Ministério da Defesa para o programa Soldado Cidadão. Tal operação estava dando problemas pelo que comportava o Sistema e o volume de matrículas, informações colocadas pelos demandantes e ofertantes, sendo 
desafio para o êxito do PRONATEC a resolução de tais problemas operacionais, os quais determinavam alocação de recursos conforme matrículas finais dos estudantes tanto da bolsa formação estudante quanto do bolsa formação trabalhador.

$\mathrm{Na}$ bolsa formação estudante correspondia as Secretarias Estaduais de Educação as instituições demandantes, sendo priorizados os estudantes de ensino médio regular do segundo ano, constituindo turmas no cuidado em evitar processos de evasão, comuns na oferta concomitante, pois consistia em situação difícil para o estudante, muitas vezes, dar conta do repertório de formação geral e do curso técnico específico, para exemplificar - de Administração, ou Agropecuária, ou Eletrotécnica - cursos constantes no Catálogo Nacional de cursos técnicos de 800 a 1.200 horas em conformidade à definição da habilitação profissional.

De certa forma, a concomitância do PRONATEC pressupõe Educação Integral para o estudante de Ensino Médio, considerando o envolvimento deste estudante com a formação geral e habilitação profissional específica. É recomendável às instituições que ofertavam a Educação geral e a Educação Profissional o monitoramento da frequência deste estudante, seu envolvimento com os cursos, para que não incorra na evasão e aí a não certificação do Ensino Técnico o qual pressupõe o Ensino Médio concluído.

$\mathrm{Na}$ bolsa formação trabalhador ocorria uma demanda significativa do Ministério de Desenvolvimento Social, das pessoas beneficiárias de programas de transferência de renda, especialmente a bolsa família e o benefício de prestação continuada - percebido pelas pessoas com alguma deficiência, conforme a lei 12.513/2011 - públicos prioritários do PRONATEC.

Constituíam-se como demandantes também o Ministério do Turismo com cursos de idiomas para a Copa do Mundo; a Secretaria de Direitos Humanos com a profissionalização dos jovens em conflito com a lei; o Ministério do Trabalho e Emprego com os 
beneficiários do Seguro Desemprego; os cursos de qualificação profissional do PRONACAMPO ${ }^{60}$.

Os gestores estaduais da Educação Profissional presentes na reunião do dia 24 de maio de 2012 reconheceram a importância da elevação de escolaridade vinculada aos cursos FIC, a fim de garantir empregabilidade como bem confirmou a pesquisa da Fundação Getúlio Vargas, referida no início do texto.

Vindo ao encontro desta discussão, estava um desafio colocado no processo de reconhecimento de saberes dos trabalhadores pela rede CERTIFIC, que ao encaminhar para elevação de escolaridade os trabalhadores, de acordo às formulações desta política, após o processo de reconhecimento de saberes o qual durava em média 200 horas com entrevista, simulação em laboratório dos procedimentos do perfil profissional. Registravam evasão do trabalhador nas turmas de elevação de escolaridade do Ensino Fundamental. O desafio estava em construir processos os quais fosse possível certificar a formação profissional e a elevação de escolaridade de Ensino Fundamental. Que os conhecimentos de um pedreiro, por exemplo, tenham mecanismos de reconhecimento dos saberes do Ensino Fundamental por aulas teóricas, práticas, materiais didáticos, os quais não necessitem da frequência às 1.200 horas aula, conforme regulamentação do decreto 5840 de 2006 e do parecer 11 de 2012 do Conselho Nacional de Educação (CNE).

Tal desafio pode ser executado em parceria pelas redes municipais, estaduais de EJA com os Institutos Federais legalmente designados à certificação profissional dos trabalhadores conforme a lei dos Institutos Federais - 11892/2008 artigo $2^{\circ}$, § 2o "No âmbito de sua atuação, os Institutos Federais exercerão o papel de institui-

${ }^{60}$ Conforme o site do Ministério da Educação a definição do PRONACAMPO: "Programa de Apoio à Formação Superior em Licenciatura em Educação do Campo - PROCAMPO". No entanto, haviam registros de ações dentro do PRONATEC para as comunidades rurais vinculadas à profissionalização das pessoas do campo. 
ções acreditadoras e certificadoras de competências profissionais." Bem como na criação de redes estaduais específicas de certificação profissional, com a aprovação do Conselho Estadual de Educação, considerando o título III capítulo II - que dispõe sobre Certificação Profissional - Resolução 06/2012 das Diretrizes Curriculares Nacionais da Educação Profissional Técnica de Nível Médio - Parecer 11/2012, podendo ser acreditado o Sistema S para este processo.

Esse compõe um desafio para o financiamento da bolsa formação trabalhador, não sendo possível oferecer formação de segunda categoria para o trabalhador no mero objetivo da "aceleração da aprendizagem", mas que a certificação profissional aprofunde o entendimento da integração da Educação Profissional à Educação Geral, no reconhecimento de que o repertório específico da Educação Profissional dependa de um repertório geral proporcionado pela Educação Básica. Tal processo pode possibilitar ao trabalhador frequentar o Ensino Técnico, constituindo itinerário formativo em conformidade à sua ocupação profissional, seus saberes de vida e de trabalho.

O exercício de pensar o tempo, de pensar a técnica, de pensar o conhecimento enquanto se conhece, de pensar o quê das coisas, o para quê, o como, o em favor de quê, de quem, o contra quê, o contra quem são exigências fundamentais de uma educação democrática à altura do nosso tempo. (Freire, 2000, p.102).

Considerando a complexidade do reconhecimento dos saberes dos trabalhadores jovens e adultos em seu processo formativo, a bolsa formação com todas suas controvérsias ${ }^{61}$, possa vir a constituir-se como um inédito viável na Educação de Jovens e Adultos trabalhadores.

61 Sendo um programa emergencial do Governo Dilma Roussef, ao que foi o Programa Intensivo de Preparação de Mão de Obra (PIPMO) idealizado pelo governo democrático de João Goulart e executado pela ditadura militar nos anos 70 do século passado, também a exemplo do Plano Nacional de Formação Profissional 


\section{Expansão da Rede Federal de Educação Profissional e Tecnológica}

Os Institutos Federais de Educação, Ciência e Tecnologia compõem uma nova institucionalidade. Regulamentados pela lei 11892 de dezembro de 2008 , compõem prerrogativa do artigo $8^{\circ}$ a oferta de $50 \%$ das matrículas em educação profissional técnica de nível médio, prioritariamente na forma de cursos integrados, para os concluintes do ensino fundamental e para o público da educação de jovens e adultos.

Tal dispositivo legal tem favorecido a oferta PROEJA, regulamentada pelo decreto presidencial 5840 de 2006 o qual prevê 10\% do quantitativo geral das matrículas da rede federal de Educação Profissional e Tecnológica para esta oferta PROEJA, sendo o referido decreto presidencial anterior a lei dos Institutos Federais.

Conforme levantamento feito em 2012, pela então equipe gestora do PROEJA da Diretoria de Políticas da Educação Profissional da SETEC do MEC, os Institutos Federais - Acre, Roraima, Pedro II e Farroupilha ofertavam mais do que o quantitativo de $10 \%$ das matrículas do PROEJA; Espírito Santo, Maranhão, Sergipe, Norte de Minas Gerais, Mato Grosso, Amazonas, Sudeste de Minas Gerais e Rio de Janeiro apresentavam de 7 a $10 \%$ de suas matrículas em PROEJA. Logo, 12 dos 39 Institutos Federais realizavam oferta PROEJA conforme o decreto 5840 de 2006.

De estrutura multicampi, atuando além do Ensino em Pesquisa e Extensão totalizaram 562 unidades em 2014, interiorizadas conforme os territórios da cidadania, com potencial para o desenvolvimento local e regional, vinculados aos arranjos produtivos culturais e

(PLANFOR) dos governos de Fernando Henrique Cardoso nos anos 90 e Plano Nacional de Qualificação Profissional (PNQ) do primeiro mandato de Lula, há muitas críticas ao PRONATEC, sobretudo a ação bolsa formação, especialmente a análise de Franzoi et al. (2013). 
econômicos, podendo significar pólos de articulação e avaliação da oferta de Educação Profissional e Tecnológica, cujos estudos sobre evasão ocorreram a partir da entrada do PROEJA como oferta, sendo desnaturalizada a evasão a qual até a instituição do PROEJA era considerada constituinte da oferta de Educação Profissional, sobretudo nos cursos da modalidade subseqüente, ou seja, uma oferta após a conclusão do Ensino Médio.

Da mesma forma, a oferta PROEJA introduziu a assistência estudantil vinculada ao acesso, à permanência e ao êxito dos estudantes aos cursos técnicos. A partir do ano de 2008 ocorria a descentralização dos valores conforme matrículas informadas pelos gestores, com a aprovação do decreto 7.234 de 19 de julho de 2010 que dispõe do Programa Nacional de Assistência Estudantil tais valores foram colocados na matriz orçamentária dos Institutos Federais a partir de 2011, representando um crescimento exponencial do alcance dos recursos da assistência estudantil, envolvendo a oferta PROEJA e demais ofertas de cursos da instituição.

Possibilitando aos jovens e adultos trabalhadores recursos para transporte escolar, material didático, moradia estudantil, os quais facilitam o acesso, a permanência e aí o efetivo sucesso das classes populares à escolarização ${ }^{62}$.

\section{Expansão do acordo de gratuidade do Sistema S}

O Sistema $\mathrm{S}$ desde sua fundação nos anos 40 do século passado até os nossos dias vem recebendo dinheiro público para investimento na Educação Profissional sem necessariamente um controle

62 A dissertação de mestrado de Noro (2011) apresenta dados da importância da assistência estudantil para o aproveitamento dos estudantes do PROEJA aos cursos. 
de sua oferta gratuita, que atualmente ocorre conforme os decretos presidenciais 6633/08 - regulamenta a oferta gratuita do SENAC e o decreto 6635/08 - regulamenta a oferta gratuita do SENAI.

Logo, é recomendável a exigência do Sistema $S$ a oferta de $10 \%$ das matrículas PROEJA, colocadas no decreto 5840 de 2006, o qual realizava elevação de escolaridade em cursos promovidos pelo SESI, estando em 766 mil e 536 matrículas ${ }^{63}$ do Ensino Fundamental incluindo a Alfabetização e Ensino Médio, cabendo a expansão desta oferta vinculada à bolsa formação trabalhador e ao acordo de gratuidade do Sistema S.

As metas do PRONATEC colocavam o quantitativo de $66 \%$ da oferta do Sistema S gratuita até 2014, considerada a expansão do acordo de gratuidade, sendo possível então o envolvimento do acordo de gratuidade do Sistema $S$ à elevação da escolaridade dos trabalhadores proporcionada pelos cursos da oferta PROEJA, ou seja, turmas de PROEJA incluídas no acordo de gratuidade do sistema S, como afirma Freire: no fundo, a educação de adultos hoje como a educação em geral não podem prescindir do exercício de pensar criticamente a própria técnica. (2000,p.102)

\section{Brasil Profissionalizado}

Estava previsto no orçamento do PRONATEC em 2012 o investimento de 340 milhões na construção e reforma de escolas técnicas estaduais, construção e equipagem de laboratórios e formação de professores e gestores em cursos de formação pedagógica e pós-graduação.

${ }^{63}$ Informações presentes na publicação Serviço Social da Indústria. Departamento Nacional. Estatísticas SESI 2006. / SESI/DN - Brasília :SESI/DN, 2007. Constante no site: http://www.portaldaindustria.com.br/cni/publicacoes-eestatisticas/publicacoes/2012/07/1,4005/estatistica-do-sesi-2006.html Acesso em 10 de outubro de 2012. 
Tal investimento poderia estar associado à expansão do PROEJA, como vinha ocorrendo no Estado da Bahia que conforme os dados do censo escolar de 2011 - compilação feita pelo DIEESE - do total de sua oferta de nível técnico de 48 mil e 739 matrículas, 6 mil e 564 correspondiam ao PROEJA Médio.

As redes estaduais correspondiam ao maior registro de matrículas da Educação Profissional de nível Técnico, no quantitativo do censo escolar de 2011 ocorreu o registro de 486 mil e 860 matrículas, constando 202 mil e 261 da rede federal e 586 mil e 831 das redes privadas - estando aí o quantitativo do Sistema S.

Caberia um tratamento diferenciado para as redes estaduais, considerando a implementação do artigo 17 da lei do PRONATEC: É criado o Conselho Deliberativo de Formação e Qualificação Profissional, com a atribuição de promover a articulação e avaliação dos programas voltados à formação e qualificação profissional no âmbito da administração pública federal, cuja composição, competências e funcionamento serão estabelecidos em ato do Poder Executivo.

Tal ato do poder executivo prescindia da consideração do papel articulador do Conselho dos Secretários Estaduais de Educação (CONSED), da significativa oferta de ensino técnico pelas redes estaduais.

\section{Educação Profissional à Distância: ETEC - Brasil}

A oferta de matrículas de PROEJA à distância, constante nos dados do SISTEC ${ }^{64}$ correspondia a 2.883 matrículas, sobretudo nos cursos vinculados à Pesca, de oferta do Instituto Federal do Paraná.

Para esta oferta, constitui o entendimento da necessária fruição à tecnologia, um preparo nos pólos presenciais do uso da platafor-

${ }^{64}$ Dados concedidos pela equipe técnica da Diretoria de Políticas da Educação Profissional e Tecnológica em maio de 2012. 
ma, do entendimento de objetos de aprendizagem, pois se a oferta de Educação à distância carece de ferramentas de monitoramento à evasão, no público trabalhador tal monitoramento necessita de um cuidado ainda maior, considerando as experiências de vida nos diferentes materiais didáticos disponibilizados.

Até 2014 estavam previstas 674 mil vagas para oferta na ação ETEC via financiamento do PRONATEC, 150 milhões de recursos previstos para as 150 mil vagas do então ano de 2012, especialmente nos Institutos Federais de Educação, Ciência e Tecnologia.

\section{Palavras Finais}

Eu só peço a Deus

Que a dor não me seja indiferente

Que a seca morte não me encontre um dia

Vazio e solitário sem ter feito o suficiente

Eu Só Peço A Deus

(Sólo le pido a Dios - Letra e Música León Gieco)

Como marca a música interpretada pela lendária cantora argentina Mercedes Sosa e colocada como epígrafe: não foram suficientes as políticas públicas de Educação Profissional para as demandas dos trabalhadores brasileiros sem Educação Básica.

Nossa herança escravocrata ainda determina o "qualquer oferta serve" na contramão do desenvolvimento econômico do país.

Há potencial para a bolsa formação no âmbito do PRONATEC, promover também elevação de escolaridade, considerando a capilaridade do Sistema $\mathrm{S}$ e das redes públicas estaduais de ensino técnico.

Há potencial para o CERTIFIC reconhecer também os saberes gerais e certificar o Ensino Fundamental, além do perfil profissional estabelecido. 
Há potencial também através da metodologia do CERTIFIC, articulada à bolsa formação do PRONATEC, na construção de um Programa Nacional de Profissionalização dos Catadores, considerando a lei da Política Nacional dos Resíduos Sólidos, n ${ }^{\circ} 12.305$ de outubro de 2010, a qual determina que não só a reciclagem passa a ser uma obrigação, como a inserção das associações ou cooperativas de trabalhadores de materiais recicláveis torna-se condicionante para o financiamento público deste setor.

Conforme tratativas estabelecidas desde o segundo semestre de 2011 da Diretoria de Políticas de EPT / SETEC / MEC com a Secretaria Nacional de Economia Solidária (SENAES) do Ministério do Trabalho e Emprego junto a Secretaria Executiva do Comitê Interministerial de Inclusão Social dos Catadores (CIISC) vinculada ao Ministério do Desenvolvimento Social, considerando o reconhecimento dos saberes dos catadores vinculados aos Galpões, Unidades de Triagem de Resíduos Sólidos, ao encaminhamento destes para cursos FIC do PRONATEC presentes já no Guia PRONATEC de Cursos e à incubação das experiências dos centros de triagem / galpões para transferência de tecnologia, sendo esta última disposição de um edital da SENAES para as instituições as quais compõe a rede federal de Educação Profissional e Tecnológica.

Desta forma o tripé: reconhecimento de saberes / elevação de escolaridade - profissionalização e incubação de experiências dos Centros de Triagem / Galpões de reciclagem na promoção da profissionalização destes cerca de 40 mil catadores de resíduos sólidos das diferentes regiões do Brasil, concentrados nas capitais dos Estados.

Há um campo de possibilidades hoje na oferta de Educação Profissional e Tecnológica na expansão do PROEJA, evitando o desfecho "Que a seca morte não me encontre um dia / Vazio e solitário sem ter feito o suficiente", na perspectiva dos inéditos viáveis freireanos para os cerca de 110 milhões de brasileiros sem Educação Básica. 


\section{Referências bibliográficas}

Brasil (2006). Decreto $n^{\circ} 5.840$, de 13 de junbo de 2006. Institui, no âmbito federal, o Programa de Integração da Educação Profissional com a Educação Básica na Modalidade de Educação de Jovens e Adultos - PROEJA, e dá outras providências.

Brasil (2010). Decreto Presidencial 7.234/2010. Dispõe sobre o Programa Nacional de Assistência Estudantil - PNAES.

Brasil (2010). Decreto Presidencial 7.404/2010. Regulamenta a Lei $N^{\circ}$ Lei 12.305, de 2 de Agosto de 2010, que institui a Política Nacional de Resíduos Sólidos, cria o Comitê Interministerial da Política Nacional de Resíduos Sólidos E o Comitê Orientador para a Implantação dos Sistemas de Logística Reversa, e dá outras providências.

Brasil (2011). Lei 12.513/2011 (Lei Ordinária) Institui o Programa Nacional de Acesso ao Ensino Técnico e Emprego (Pronatec) 26/10/2011.

Brasil (2012). Lei 12.593/2012 (Lei Ordinária) 18/01/2012. Institui o Plano Plurianual da União para o Período de 2012 a 2015.

Brasil (2012). Lei 12.677/2012. Dispõe sobre a Criação de Cargos Efetivos, Cargos de Direção e Funções Gratificadas no Âmbito do Ministério da Educação, destinados às Instituições Federais de Ensino.

Brasil (2012). Guia PRONATEC de Cursos FIC. Disponível em: http://pronatec.mec. gov.br/guia_cursos.html, acesso em 10 de junho de 2012.

Brasil (2014). Lei 13.005/2014. Aprova o Plano Nacional de Educação - PNE e dáoutras providências.

Brasil, Ministério da Educação (2009). Portaria Interministerial $N^{\circ} 1.082$, de 20 de Novembro de 2009.

Brasil, Ministério da Educação. Secretaria de Educação Profissional com a Educação Básica na modalidade Educação de Jovens e Adultos (2007). Educação Indígena. Documento Base (agosto de 2007).

Brasil, Ministério da Educação, Secretaria de Educação Profissional com a Educação Básica na modalidade Educação de Jovens e Adultos. (2007). Formação inicial e continuada / Ensino Fundamental. Documento Base (agosto de 2007).

Brasil, Ministério da Educação. Secretaria de Educação Profissional e Tecnológica (2006). Programa de Integração da Educação Profissional Técnica de Nível Médio ao Ensino Médio na Modalidade de Educação de Jovens e Adultos. PROEJA. Documento Base.

Câmara de Educação Básica (2012). Parecer 11/2012 - Dispõe sobre as Diretrizes Curriculares Nacionais para a Educação Profissional Técnica de Nível Médio.

CNE (2012). Parecer 11 de 2012 - Diretrizes Curriculares Nacionais para a Educação Profissional Técnica de Nível Médio.

Franzoi, N. L. et al. (2013) PROEJA e PRONATEC: ciclo de políticas, políticas recicladas. Políticas Educativas, 6(2).

Freire, P. (1997). Pedagogia da Esperança. São Paulo: Editora Paz e Terra.

Freire, P. (2000) Pedagogia da Indignação - cartas pedagógicas e outros escritos. São Paulo: Editora UNESP. 
Neri, M. (2012). As razões da Educação Profissional: olhar da demanda. Rio de Janeiro, FGV/CPS.

Noro, M. (2011). Gestão de Processos Pedagógicos no PROEJA: razão de acesso e permanência. Porto Alegre: Programa de Pós-Graduação em Educação / Faculdade de Educação - UFRGS.

PDE Interativo - Plano de Desenvolvimento da Escola. (2012). Disponível em: http:// pdeescola.mec.gov.br/index.php?option=com_content\&view=article\&id=97, acesso em 10 de junho de 2012.

Programa Mulheres Mil (2012). Disponível em: http://mulheresmil.mec.gov.br/, acesso em 10 de junho de 2012.

Serviço Social da Indústria. (2007). Departamento Nacional. Estatísticas SESI 2006 /SESI/DN. Brasília: SESI/DN. Disponível em: http://www.portaldaindustria.com. $\mathrm{br} / \mathrm{cni} /$ publicacoes-e estatisticas/publicacoes/2012/07/1,4005/estatistica-do-sesi-2006.html, acesso em 10 de outubro de 2012

Silva, J. M. (2013). Certificação Profissional de trabalhadores e trabalhadoras de materiais recicláveis: reflexões para a construção de uma política pública. Dissertação de Mestrado. Porto Alegre: Programa de Pós-Graduação em Educação - UFRGS. 